\title{
Tumor exome sequencing and copy number alterations reveal potential predictors of intrinsic resistance to multi-targeted tyrosine kinase inhibitors
}

\author{
Nancy K. Gillis ${ }^{1,2,3}$, Daniel M. Rotroff ${ }^{4}$, Tania E. Mesa ${ }^{5}$, Jiqiang Yao ${ }^{6}$, Zhihua Chen ${ }^{6}$, \\ Michael A. Carulli7, Sean J. Yoder ${ }^{5}$, Christine M. Walko ${ }^{1,2}$, Jamie K. Teer ${ }^{8}$ and \\ Howard L. McLeod ${ }^{1,2}$ \\ ${ }^{1}$ DeBartolo Family Personalized Medicine Institute, H. Lee Moffitt Cancer Center and Research Institute, Tampa, FL, USA \\ ${ }^{2}$ Department of Cancer Epidemiology, H. Lee Moffitt Cancer Center and Research Institute, Tampa, FL, USA \\ ${ }^{3}$ Center for Pharmacogenomics and Individualized Therapy Eshelman School of Pharmacy, University of North Carolina, \\ Chapel Hill, NC, USA \\ ${ }^{4}$ Bioinformatics Research Center, North Carolina State University, Raleigh, NC, USA \\ ${ }^{5}$ Molecular Genomics Core, H. Lee Moffitt Cancer Center and Research Institute, Tampa, FL, USA \\ ${ }^{6}$ Cancer Informatics Core, H. Lee Moffitt Cancer Center and Research Institute, Tampa, FL, USA \\ ${ }^{7}$ College of Pharmacy, University of South Florida, Tampa, FL, USA \\ ${ }^{8}$ Department of Biostatistics and Bioinformatics, H. Lee Moffitt Cancer Center and Research Institute, Tampa, FL, USA \\ Correspondence to: Howard L. McLeod, email: Howard.McLeod@moffitt.org \\ Keywords: tyrosine kinase inhibitors; resistance; somatic genetics; intrinsic; copy number \\ Received: September 06, $2017 \quad$ Accepted: November 05, $2017 \quad$ Published: December 04, 2017 \\ Copyright: Gillis et al. This is an open-access article distributed under the terms of the Creative Commons Attribution License 3.0 \\ (CC BY 3.0), which permits unrestricted use, distribution, and reproduction in any medium, provided the original author and source \\ are credited.
}

\section{ABSTRACT}

Multi-targeted tyrosine kinase inhibitors (TKIs) have broad efficacy and similar FDA-approved indications, suggesting shared molecular drug targets across cancer types. Irrespective of tumor type, $\mathbf{2 0 - 3 0 \%}$ of patients treated with multi-targeted TKIs demonstrate intrinsic resistance, with progressive disease as a best response. We conducted a retrospective cohort study to identify tumor (somatic) point mutations, insertion/deletions, and copy number alterations (CNA) associated with intrinsic resistance to multi-targeted TKIs. Using a candidate gene approach $(n=243)$, tumor next-generation sequencing and CNA data was associated with resistant and nonresistant outcomes. Resistant individuals $(n=11)$ more commonly harbored somatic point mutations in NTRK1, KDR, TGFBR2, and PTPN11 and CNA in CDK4, CDKN2B, and $E R B B 2$ compared to non-resistant $(n=26, p<0.01)$. Using a random forest classification model for variable reduction and a decision tree classification model, we were able to differentiate intrinsically resistant from non-resistant patients. CNA in CDK4 and CDKN2B were the most important analytical features, implicating the cyclin D pathway as a potentially important factor in resistance to multi-targeted TKIs. Replication of these results in a larger, independent patient cohort has potential to inform personalized prescribing of these widely utilized agents.

\section{INTRODUCTION}

Increasing evidence supports the classification of tumors based on genetic and molecular characteristics rather than site of origin, which has translated into the ability to predict drug response utilizing tumor genetics rather than tumor type (i.e., histology or site of origin) in some instances [1]. For example, using multiple genetic platforms, The 
Cancer Genome Atlas Research Network defined four molecular subtypes of breast cancer (Luminal A, Luminal B, HER2-enriched, and Basal-like) and found that one subtype (Basal-like) is more similar to serous ovarian cancer than to other breast cancers [2]. Further analysis showed that, due to their molecular similarities, Basal-like breast cancers and serous ovarian cancers are likely susceptible to similar targeted treatments. In another multiplatform analysis of twelve tissue-defined cancer types, eleven major subtypes were identified, with only five subtypes corresponding to their tissue of origin, and the remaining six subtypes being shared by distinct cancer types (e.g., lung squamous, head and neck, and some bladder cancers fell into a single subtype) [3]. Studies such as these have influenced clinical cancer drug development. The classification and treatment of tumors based on molecular alterations is currently being studied through the use of basket trials, such as NCI-MATCH and NCI-MPACT, which randomize patients to an individualized targeted therapy arm or a non-pathway-specific arm independent of tumor histology [4]. We hypothesize that genetic alterations within tumors, regardless of site of origin or histology, can be used as a biomarker of response to targeted anticancer therapies.

The broad efficacy of multi-targeted tyrosine kinase inhibitors (TKIs) across tumor types suggests similarities in the genetics of the tumors they are used to treat. The multi-targeted TKIs (i.e., axitinib, cabozantinib, pazopanib, regorafenib, sorafenib, sunitinib, and vandetanib) currently have FDA-approved indications in seven histological tumor types, and are used off-label in additional solid and hematologic malignancies. While the clinical trials of these agents demonstrated overall efficacy, a substantial number of individuals never responded to therapy. This is a clinical challenge for most targeted anticancer agents [5]. In the pivotal phase III clinical trials that led to approval of each of the multi-targeted TKIs, approximately 20 to $30 \%$ of patients showed a best response of progressive disease, demonstrating intrinsic resistance [6-13]. In an exploratory study $(n=262)$ examining intrinsic resistance to multi-targeted TKIs across tumor types, we observed an intrinsic resistance rate of $21 \%$, consistent with that seen in clinical trials (unpublished data). No patient demographic or clinical factors (e.g., tumor type or drug received) were associated with intrinsic resistance. This supports the hypothesis that genetic factors may be important in predicting intrinsic resistance to the multi-targeted TKIs. We conducted a retrospective case-control study using a candidate gene approach to identify somatic point mutations, insertions/deletions, and copy number alterations (CNAs) associated with resistance to multi-targeted TKIs across tumor types.

\section{RESULTS}

\section{Patient population and phenotypes}

A total of 50 unique patients were included in this study (Table 1). The average age was 60 years old and the majority of individuals were white $(88 \%)$ non-Hispanic $(90 \%)$ males $(72 \%)$. The most common tumor types being treated were sarcoma (48\%) and renal cell carcinoma $(40 \%)$, as would be expected, and the majority of patients received pazopanib (38\%), followed by sorafenib (30\%) and sunitinib $(28 \%)$. One patient received regorafenib and one axitinib. Of the 50 patients included, $11(22 \%)$ were classified as resistant, $26(52 \%)$ as non-resistant, and 13 had unclassifiable responses. This corresponded to an overall resistance rate of $30.5 \%(11 / 36)$ observed in our cohort. After correcting for multiple comparisons using false discovery rate (FDR), there were no statistically significant differences in the demographic and clinical characteristics of resistant and non-resistant patients. Resistant patients discontinued multi-targeted TKIs significantly sooner than non-resistant patients $\mathrm{did}(\mathrm{U}=$ $14.5, \mathrm{p}<0.0001$, Figure 1).

\section{Next-generation sequencing: quality control}

A total of 24 samples underwent targeted exome sequencing under the TCC protocol. The target region was 1,321 genes covering 3.8 Mb. The median number of reads aligned per sample was 15,283,830. Median read depth of coverage was $141 \mathrm{x}$. A median of $93.7 \%$ of coding bases were covered at least 10x across samples. For the 25 tumor samples that underwent WES, an average coverage of $151 \mathrm{x}$ (95\% CI 140 - 163) per base was achieved. The average total number of reads per sample was $1.83 \times 10^{8}(95 \% \mathrm{CI}$ $1.75 \times 10^{8}-1.92 \times 10^{8}$ ) or 91.5 million paired-end reads, with an average of $20 \%$ duplicate reads and $98 \%$ of reads mapped to the human reference genome. After removing duplicates, paired-end reads were properly paired overall (average per sample 94\%). An average of 74,349 variants (point mutations and insertion/deletions) were detected per sample, of which 22,993 (31\%) were within coding regions of the genome, and 11,590 (16\%) were non-synonymous variants. There were five genes (CDK12, FGFR4, MLL2, $L R P 1 B$, and $A R A F$ ) with significant variation by sequencing method (FDR-corrected p-values all $<0.005$ ), warranting exclusion from further analyses. Four genes (BRCA2, $C D K 12, M L L 2$, and $V H L$ ) were differentially mutated (p-value $<0.05$ ) between renal cell carcinoma patients and sarcoma patients; however, these differences were not significant when correcting for multiple comparisons (FDR q-values $>0.5$ ).

\section{Next-generation sequencing: genetic associations}

We identified four genes (NTRK1, KDR, TGFBR2, and PTPN11) more commonly mutated in resistant patients than non-resistant patients (Figure 2A). The finding with the lowest $\mathrm{p}$-value was NTRK1, in which 3 $(30 \%)$ resistant patients carried somatic coding mutations ( 2 point mutations and 1 splice site variant) versus zero non-resistant patients $(\mathrm{p}=0.02)$. Nonsynonymous coding mutations in KDR, PTPN11, and TGFBR2 were present 
Table 1: Patient demographics $(\mathbf{n}=\mathbf{4 9})$. Demographics are broken down by phenotype for individuals who underwent next-generation sequencing $(n=37)$ and copy number alteration analysis $(n=29)$

\begin{tabular}{|c|c|c|c|c|c|c|c|}
\hline \multirow[b]{2}{*}{ Characteristic } & \multicolumn{4}{|c|}{ Next-generation sequencing } & \multicolumn{3}{|c|}{ Copy number alteration } \\
\hline & $\begin{array}{c}\text { All } \\
\text { patients } \\
(\mathrm{n}=\mathbf{5 0})\end{array}$ & $\begin{array}{l}\text { Resistant } \\
(\mathrm{n}=11)\end{array}$ & $\begin{array}{c}\text { Non- } \\
\text { resistant } \\
(n=26)\end{array}$ & $\begin{array}{l}\text { P-value } \\
\text { (FDR) }^{\#}\end{array}$ & $\begin{array}{l}\text { Resistant } \\
\quad(n=8)\end{array}$ & $\begin{array}{c}\text { Non-resistant } \\
(\mathrm{n}=\mathbf{2 1})\end{array}$ & P-value (FDR) \\
\hline Age $^{*}$ & & & & 0.19 & & & 0.06 \\
\hline Mean $\pm \mathrm{SD}$ & $60.2 \pm 12$ & $\begin{array}{c}55.2 \pm \\
13.1\end{array}$ & $\begin{array}{c}61.2 \pm \\
12.6\end{array}$ & $(0.39)$ & $\begin{array}{c}52.9 \pm \\
13.9\end{array}$ & $63.1 \pm 11.3$ & $(0.09)$ \\
\hline Median & 62 & 61 & 62.0 & & 58.5 & 66 & \\
\hline Range & $34-80$ & $36-70$ & $34-80$ & & $36-68$ & $39-80$ & \\
\hline Sex & & & & 0.05 & & & 0.03 \\
\hline Male & $36(72)$ & $7(63.6)$ & $24(92.3)$ & $(0.15)$ & $4(50)$ & $19(90.5)$ & $(0.07)$ \\
\hline Female & $14(28)$ & $4(36.3)$ & $2(7.7)$ & & $4(50)$ & $2(9.5)$ & \\
\hline Race & & & & 0.66 & & & 0.27 \\
\hline White & $44(88)$ & $10(90.9)$ & $24(92.3)$ & $(0.80)$ & $7(87.5)$ & $21(100)$ & $(0.33)$ \\
\hline Black & $3(6)$ & $1(9.1)$ & 0 & & $1(12.5)$ & 0 & \\
\hline Asian & $2(4)$ & 0 & $1(3.8)$ & & 0 & 0 & \\
\hline Unknown & $1(2)$ & 0 & $1(3.8)$ & & 0 & 0 & \\
\hline Ethnicity & & & & $1.0(1.0)$ & & & 0.48 \\
\hline Hispanic & $5(10)$ & $1(9.1)$ & $3(11.5)$ & & $1(12.5)$ & $1(4.8)$ & $(0.48)$ \\
\hline Non-Hispanic & $45(90)$ & $10(90.9)$ & $23(88.5)$ & & 7 (87.5) & $20(95.2)$ & \\
\hline Cancer type & & & & 0.03 & & & 0.007 \\
\hline Sarcoma & $24(48)$ & $6(54.5)$ & $9(34.6)$ & $(0.15)$ & $4(50)$ & $5(23.8)$ & $(0.04)$ \\
\hline $\begin{array}{l}\text { Renal cell } \\
\text { carcinoma }\end{array}$ & $20(40)$ & $2(18.2)$ & $16(61.5)$ & & $1(12.5)$ & $15(71.4)$ & \\
\hline Hepatic & $3(6)$ & $1(9.1)$ & $1(3.8)$ & & $1(12.5)$ & $1(4.8)$ & \\
\hline Breast & $1(2)$ & $1(9.1)$ & 0 & & $1(12.5)$ & 0 & \\
\hline Colorectal & $1(2)$ & $1(9.1)$ & 0 & & $1(12.5)$ & 0 & \\
\hline Melanoma & $1(2)$ & 0 & 0 & & 0 & 0 & \\
\hline $\begin{array}{l}\text { Multi-targeted } \\
\text { TKI }\end{array}$ & & & & 0.44 & & & 0.03 \\
\hline Pazopanib & $19(38)$ & $5(45.5)$ & $7(26.9)$ & $(0.66)$ & $4(50)$ & $4(19.0)$ & $(0.07)$ \\
\hline Sorafenib & $15(30)$ & $3(27.3)$ & $10(38.5)$ & & $3(37.5)$ & 9 (42.9) & \\
\hline Sunitinib & $14(28)$ & $2(18.2)$ & $8(30.8)$ & & 0 & $8(38.1)$ & \\
\hline Axitinib & $1(2)$ & 0 & $1(3.8)$ & & 0 & 0 & \\
\hline Regorafenib & $1(2)$ & $1(9.1)$ & 0 & & $1(12.5)$ & 0 & \\
\hline
\end{tabular}

${ }^{*}$ Age represents the age at multi-targeted TKI initiation.

\#P-value for continuous variables represents the logistic regression p-value and categorical data was compared between resistant and non-resistant individuals using Fisher's exact test. FDR represents the FDR-corrected p-value. 


\section{Time to TKI Discontinuation}

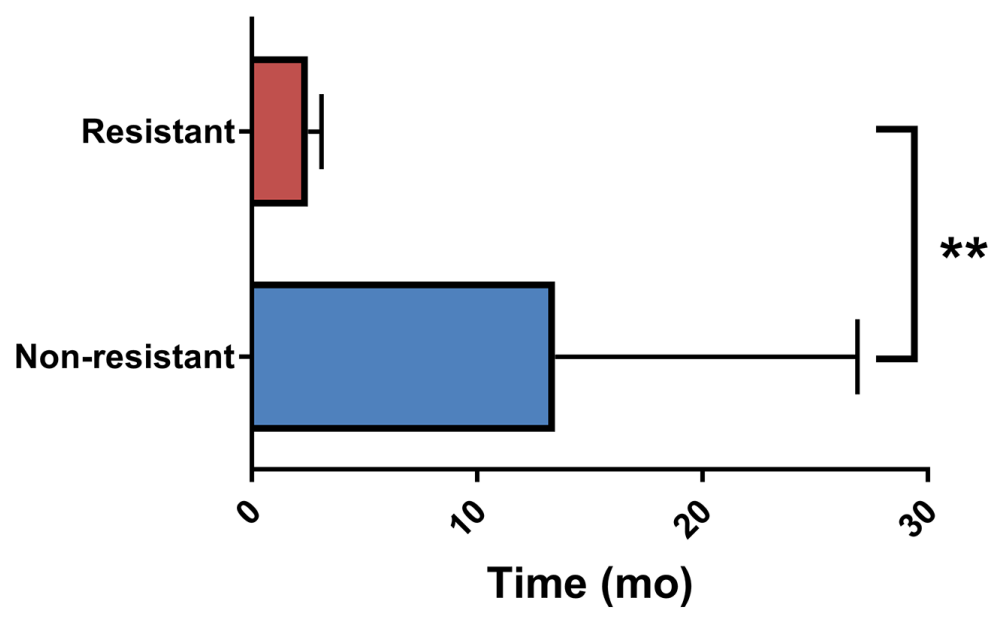

Figure 1: Time to multi-targeted tyrosine kinase inhibitor discontinuation. Data represents mean and standard deviation. ${ }^{* *}$ Mann-Whitney U p-value $<0.0001$.

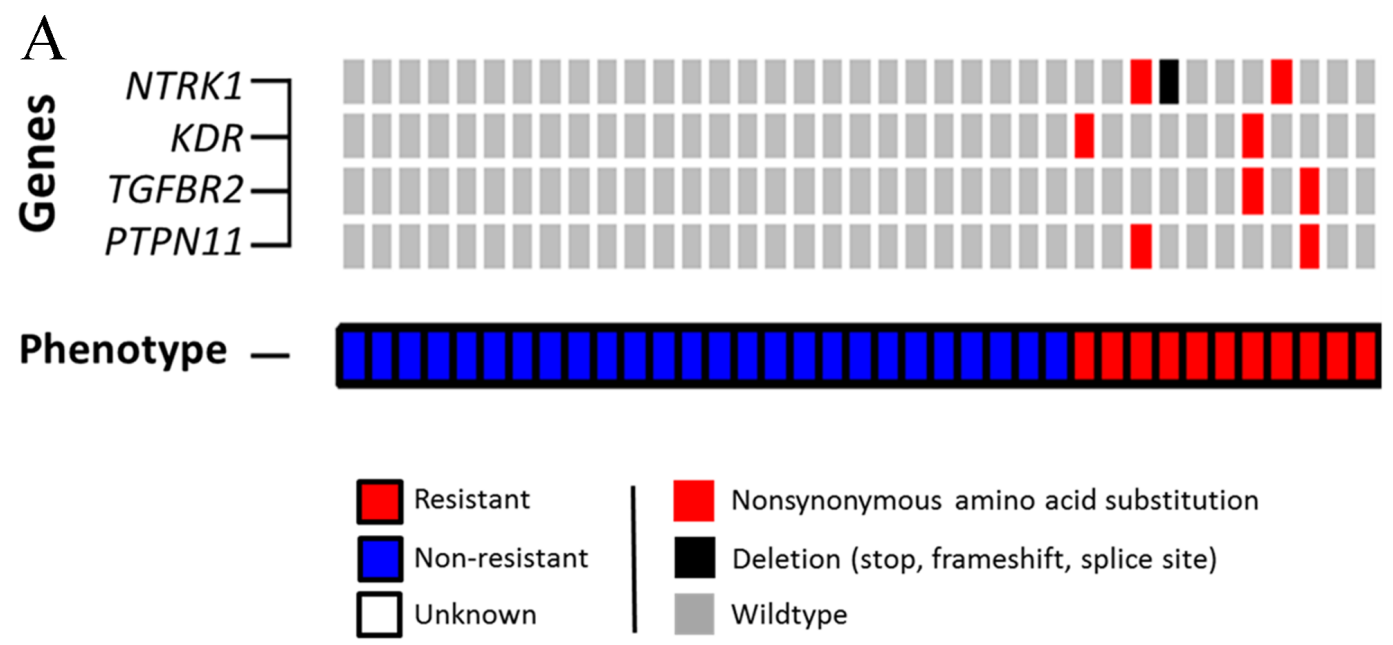

B

Mutation status of top four gene hits

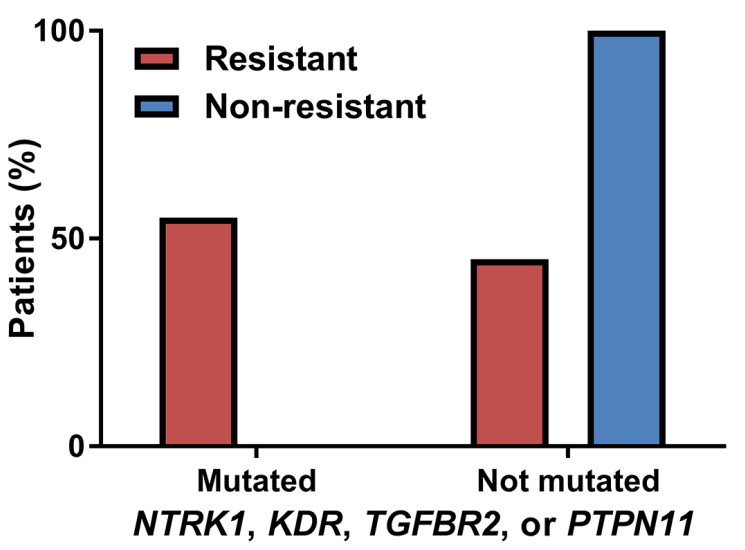

Figure 2: Differences in next-generation sequencing variants. (A) OncoPrint of somatic nonsynonymous point mutations and insertions/deletions observed differentially by phenotype. (B) Distribution of somatic nonsynonymous point mutations or splice site variants in the four key genes. 
in two $(20 \%)$ resistant patients and zero non-resistant patients $(\mathrm{p}=0.08)$. Altogether, $55 \%$ of resistant patients harbored mutations in one or more of these genes, while zero non-resistant patients carried mutations in these genes (Fisher's exact p-value $=0.0002$, Figure 2B). Gene set enrichment identified trends of receptor binding, activity, protein kinase, tyrosine, and transmembrane within the top gene hits. Of the four top hits, KDR and PTPN11 were included in screening 1,001 cancer cell lines in the Genomics in Drug Sensitivity in Cancer database [14, 15]. Presence of $K D R$ mutations was consistently predicted to confer resistance to multi-targeted TKIs, while presence of PTPN11 mutations tended to predict sensitivity to multitargeted TKIs.

\section{Copy number alterations}

Somatic CNA data was generated for 29 individuals, of which $8(27.6 \%)$ were classified as resistant. All samples resulted in data that met prespecified quality control criteria. Individuals exhibited a diverse range of somatic CNAs, with some individuals demonstrating much more genomic instability than others. A total of $55(22.6 \%)$ genes harbored CNAs that met specified filtering criteria (Figure 3). No genes met the FDR-corrected significance level; however, three genes $(C D K 4, C D K N 2 B$, and $E R B B 2)$ met the exploratory cut-off (FDR-corrected $\mathrm{p}<0.3$ ). CNAs in $C D K N 2 B$ were only observed in resistant patients, while CNAs in CDK4 and ERBB2 were less common in resistant patients (only non-resistant patients harbored CNAs in ERBB2). All of the CNAs in $C D K N 2 B$ and $E R B B 2$ were homozygous losses, and the majority $(14 / 16,87.5 \%)$ of aberrations in $C D K 4$ were also losses. Gene set enrichment identified cancer pathways, cyclin, and kinase as network trends between the three gene hits for CNA.

\section{Decision tree for combined data}

The most informative CNA and next-generation sequencing features from the random forest classification model were used to generate a decision tree for identifying resistant individuals. After quality control, data for 29 individuals with sequencing and CNA results were included in the construction of the final tree. Five genes (CDKN2B, CDK4, TGFBR2, EPHA3, and TNFAIP3) were identified as important for differentiating resistant from non-resistant individuals and were selected as features in the final decision tree (Figure 4). CNA in $C D K N 2 B$ and $C D K 4$ were the most informative and explained responses for $55 \%(16 / 29)$ of the population. Interestingly, in measuring the importance of variables using the mean decrease in Gini score, all gene hits from individual sequencing (NTRK1,KDR, TGFBR2, and PTPN11) and CNA (CDK4, CDKN2B, and ERBB2) analysis were identified as being amongst the most informative variables (Figure 4, Supplementary Table 2). The decision tree model resulted in a high sensitivity and specificity for differentiating resistant individuals (0.75 and 1 , respectively; balanced accuracy 0.88 ); however, leaveone-out cross-validation (LOOCV) resulted in a lower sensitivity and specificity $(0.25$ and 0.95 , respectively; balanced accuracy 0.6), indicating that the model constructed on all of the data is overfitting. Although the sensitivity dropped substantially after LOOCV, model specificity remained high, suggesting these features are robustly able to distinguish non-resistant samples in this rather small cohort. It further suggested that having the identified combination of mutations increases one's odds of being resistant (OR 6.67), however this result was not statistically significant ( $p>0.05)$. These features may be good candidates for follow-up analysis, but extensive external validation and larger sample sizes will be needed to develop a more clinically relevant predictive model.

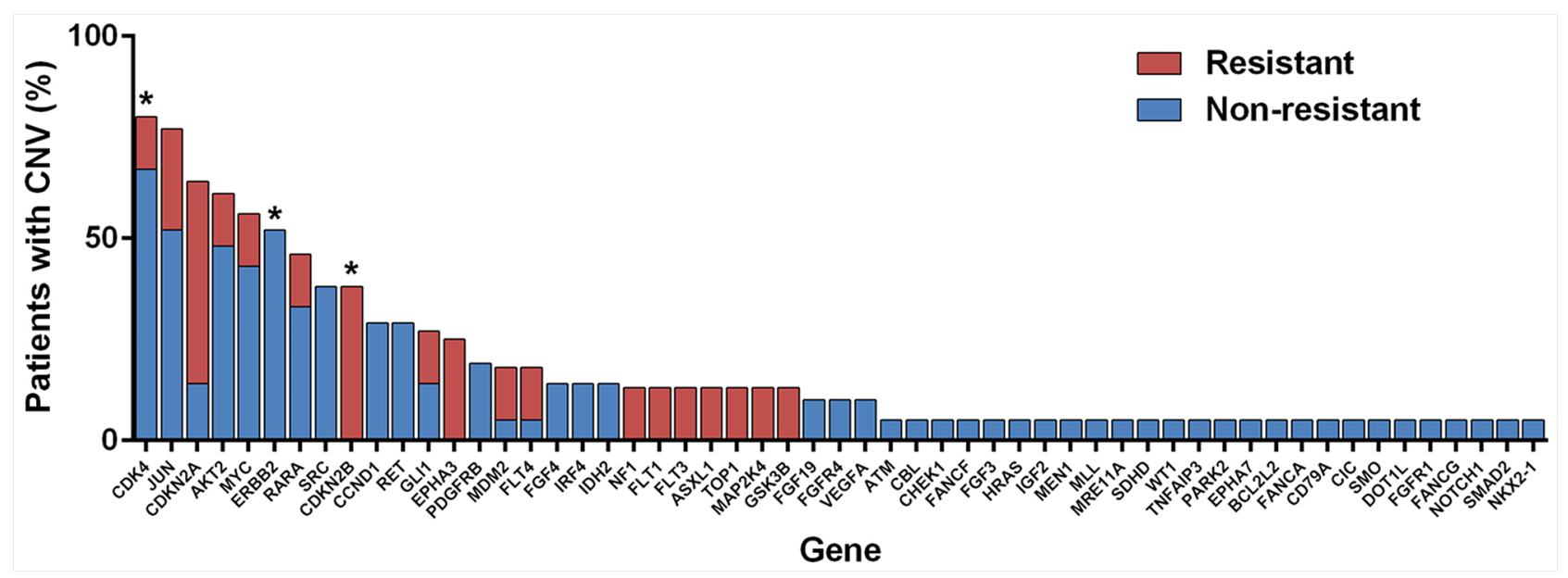

Figure 3: Copy number alterations (CNAs) observed by phenotype. *Genes that met pre-specified cut-off for exploratory hits (i.e., differential CNAs between resistant and non-resistant individuals). 


\section{DISCUSSION}

We conducted a retrospective candidate gene study to identify somatic point mutations and copy number alterations associated with intrinsic resistance to multitargeted TKIs. Using next-generation sequencing, we identified four genes commonly mutated in resistant patients, but not mutated in non-resistant patients: NTRK1, KDR, TGFBR2, and PTPN11. Interestingly, three of the four top hits (TGFR, KDR, and NTRK1) encode transmembrane protein kinases that are known targets of multi-targeted TKIs to varying degrees. The final gene, PTPN11, encodes SHP2, a tyrosine phosphatase that mediates signaling of oncogenic tyrosine kinases, such as Ras-ERK-AKT signaling pathways.

All four of the top gene hits from sequencing analysis are known to be mutated in cancer patients and have some literature suggesting possible associations with resistance and/or prognosis. $K D R$ encodes the vascular endothelial growth receptor 2 (VEGFR2), a tyrosine kinase that mediates VEGF-induced endothelial proliferation, survival, and migration. $K D R$ is commonly mutated across cancer types, and is one of the primary targets of the multitargeted TKIs, with up to eighty percent of activity being inhibited by TKIs [16]. Therefore, mutations in the gene encoding VEGFR2 represent a plausible mechanism of resistance to these agents. In fact, escape from VEGFR2 signaling dependency has been proposed as a mechanism of acquired resistance to the multi-targeted TKIs [17]. In a recent retrospective analysis of archived renal cell carcinoma patients treated with sunitinib, Stubbs and colleagues found no association between $K D R$ expression and overall or progression-free survival, but did not assess mutations [18]. However, a retrospective study of 275 sarcoma patients identify a significant correlation between high VEGFR2 protein expression and decreased patient survival $(\mathrm{p}<0.001)$ [19].

The most common NTRK1 alterations observed in cancer are gene fusions; however, point mutations have also been reported in numerous solid tumors [20, 21]. Multiple studies have linked NTRK1 overexpression to tumor progression and poor outcomes in solid cancers [22-24], and NTRK1 mutations confer acquired resistance to NTRK inhibitors [25]. Somatic mutations of TGFBR2 are commonly observed across solid tumor types [20, 21]. The majority of studies exploring the clinical significance of TGFBR2 mutations are in the context of breast cancer, where high expression of TGFBR2 is associated with tumor metastasis and response to chemotherapy [26-28]. Associations between somatic TGFBR 2 alterations and cancer progression occur in a range of solid tumor types, including gastric, bladder, and squamous cell carcinoma [29-31]. PTPN11 mutations are most commonly associated with Noonan syndrome and juvenile myelomonocytic leukemia; however, activating somatic mutations have been observed in solid tumors,

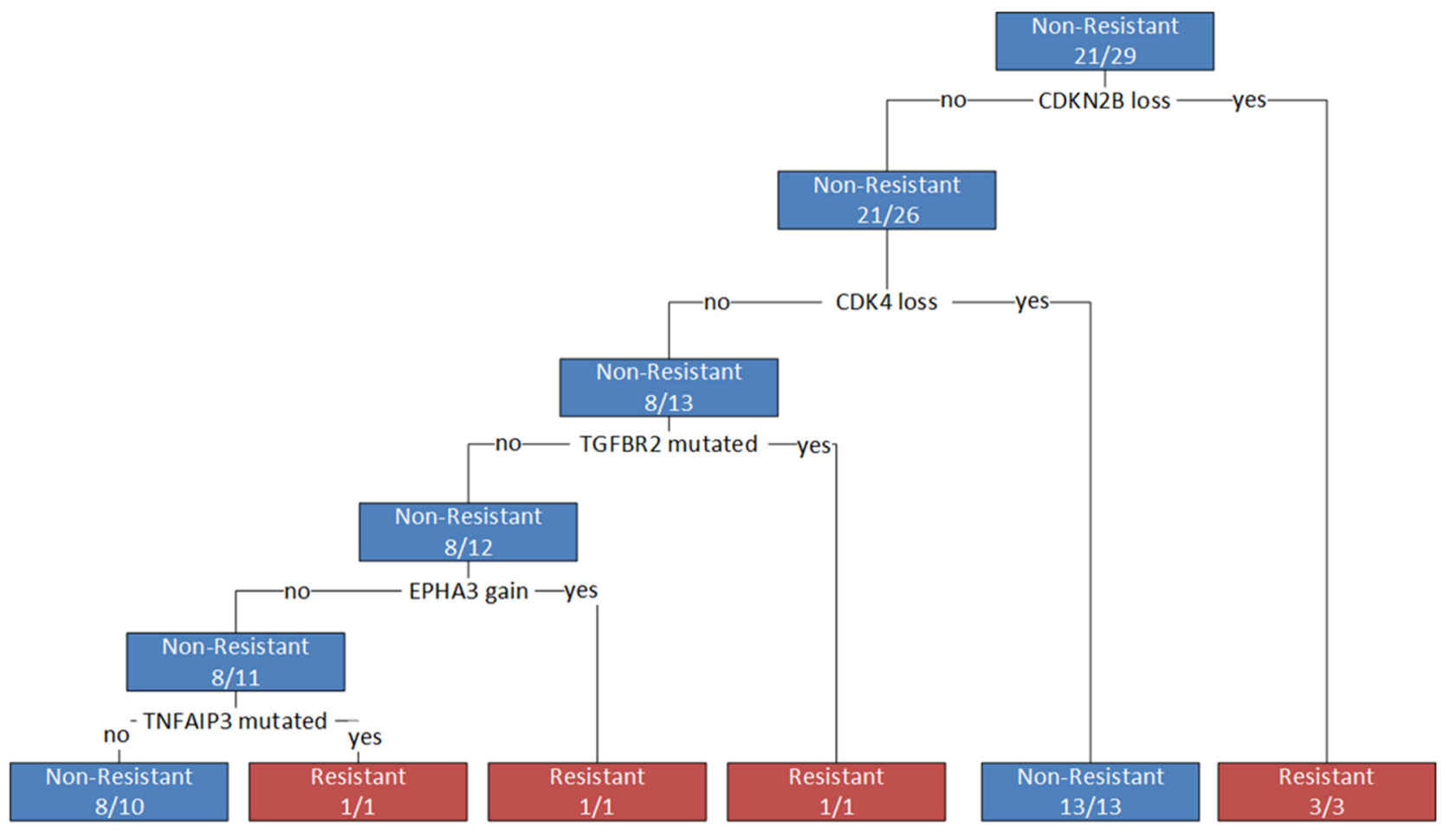

Figure 4: Decision tree for differentiating resistant from non-resistant patients. Branches represent decisions based on genes identified as influential in differentiating phenotypes. A loss represents a homozygous copy number loss; a gain represents a copy number gain greater than seven; a mutation represents any non-synonymous or missense mutation in a coding region of the gene. 
including colorectal, breast, and renal cell carcinomas $[20,21]$. These mutations enhanced cancer progression, invasion, and metastasis [32-34] and were associated with decreased response rates in hepatocellular carcinoma, glioma, and gastric cancers $[32,35,36]$. In an elegant in vitro study that utilized colon and melanoma cancer cells, Prahallad and colleagues demonstrated that PTPN11 activating mutations were present in the setting of both intrinsic and acquired resistance and that inhibition of PTPN11 is lethal in cancer cells driven by activated tyrosine kinases [37].

We identified three genes $(C D K 4, C D K N 2 B$, and $E R B B 2$ ) with differential patterns of CNAs between resistant and non-resistant patients. Interestingly, $C D K 4$ and $C D K N 2 B$ both encode for proteins involved in the cyclin-dependent (cyclin D) pathway, which regulates progression through the cell cycle. The cyclin D pathway is commonly dysregulated in solid malignancies through somatic copy number alterations [38]. In our cohort, we observed a higher frequency of $C D K N 2 B$ losses in resistant patients, while non-resistant patients more commonly harbored losses in CDK4 (Figure 5). Biologically, CDK4 functions as a positive regulator of the cell cycle, while CDKN2B is a negative regulator. Therefore, loss of $C D K 4$ results in cell cycle arrest and tumor cell senescence, while loss of $C D K N 2 B$ maintains cell cycle progression and tumor cell growth. The CNAs observed in our cohort suggest that cyclin D regulation may serve as an important secondary or bypass track for cancer progression in individuals treated with multitargeted TKIs. In fact, reduced expression of CDKN2A (a tumor suppressor protein similar to CDKN2B), has been observed in sarcoma progression and correlated with reduced patient survival [39]. ERBB2 encodes HER2, a transmembrane tyrosine kinase that regulates the PI3K/ AKT pathway upstream of mTOR. Interestingly, after therapeutic failure with multi-targeted TKIs, mTOR inhibitors are recommended as treatment options. We observed that patients non-resistant to multi-targeted TKIs more commonly harbored $E R B B 2$ losses, which suggests that mTOR may not be overregulated in these individuals, but perhaps is an important mechanism of tumorigenesis in the resistant patients.

The combination of using random forest classification models for variable reduction and constructing a decision tree using the combined nextgeneration sequencing and CNA results generated a translatable model. The genetic alterations that were identified as being most informative were CNAs in $C D K N 2 B$ and $C D K 4$, further supporting a potential roll of the cyclin D pathway in resistance to multi-targeted TKIs. EPHA3 and TNFAIP3 were identified as important

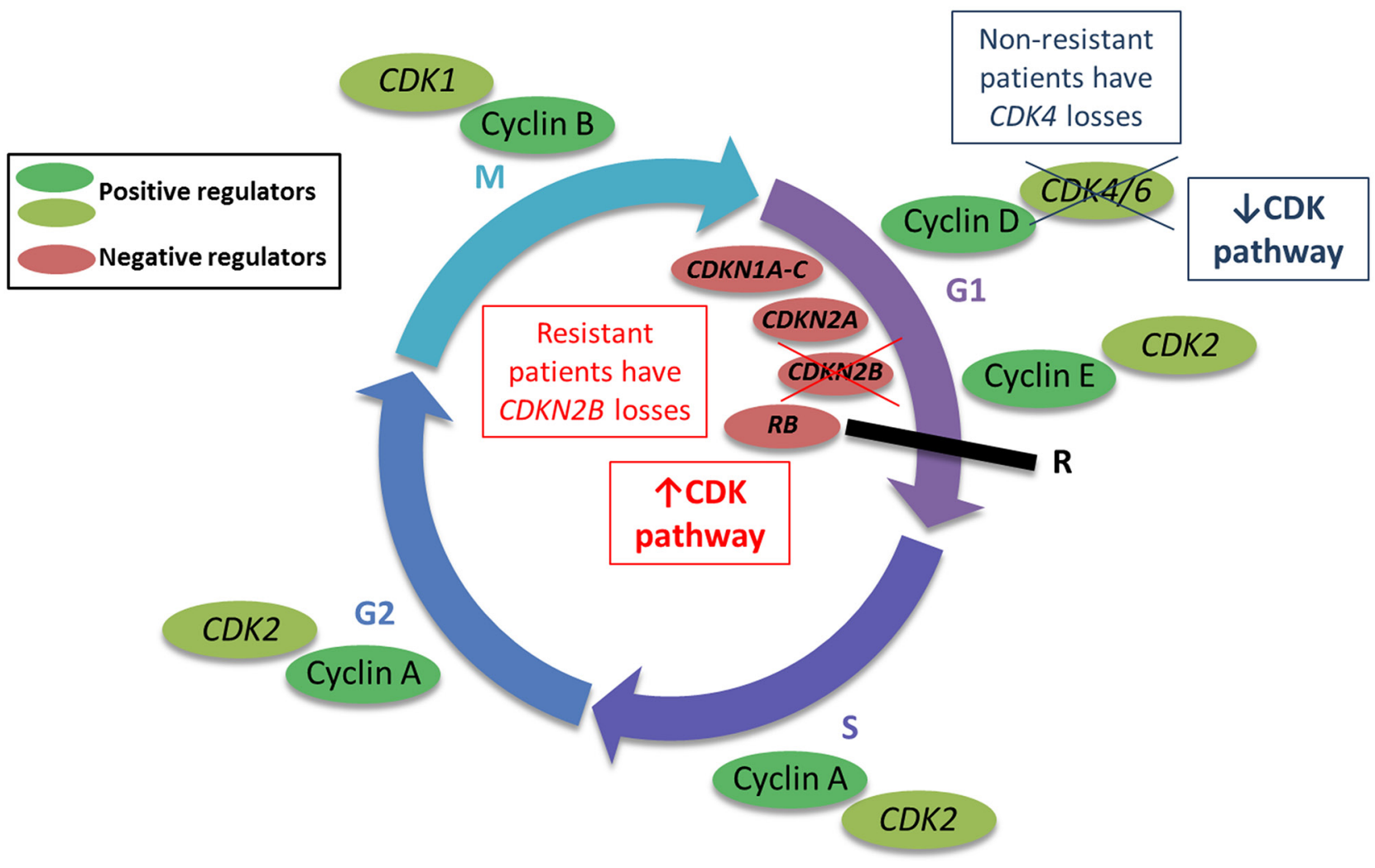

Figure 5: Copy number alterations (CNAs) in the cyclin-dependent (cyclin D) pathway may regulate progression through the cell cycle. The cyclin D pathway regulates progression through the cell cycle, ultimately regulating cell division (mitosis, or M phase). The CNAs in genes relevant to this pathway may modulate cell cycle progression as depicted in the figure. 
based on the random forest classification model, but were not identified in separate next-generation sequencing or CNA analyses; however, both of these genes have been previously associated with prognosis and resistance. EPHA3 encodes a protein tyrosine kinase receptor and its expression has been associated with high invasive capacity and poor overall survival in hepatocellular carcinoma, gastric cancer, and glioblastoma [40-42]. Additionally, EPHA3 has been associated with the regulation of multidrug resistance in small cell lung cancer via the PI3K/ BMX/STAT3 signaling pathway [43]. TNFAIP3 encodes a zinc finger protein that serves as a tumor suppressor through its potent inhibition of the $\mathrm{NF}-\kappa \mathrm{B}$ signaling pathway [44]. TNFAIP3 has also been associated with regulating drug resistance in multiple solid tumor types $[45,46]$. Therefore, dysregulation of these genes represents a biologically plausible mechanism of intrinsic resistance to multi-targeted TKIs.

While the decision tree explained our data well, it appears to be overfitted based on the reduced performance with $\mathrm{LOOCV}$, indicating that additional research is needed to develop a model that will be predictive of patient outcomes. A larger cohort is needed to robustly predict intrinsic resistance in independent datasets. Although this model is not robust enough for clinical use, we believe the five genes identified as being the most important for distinguishing resistant samples are strong candidates for additional follow-up analysis.

The most notable limitation of this study is the sample size. To address this limitation, we elected to use a candidate gene approach to decrease the multiple testing burden. While this was a good method for increasing statistical power, limitations to the candidate gene approach exist, with the main disadvantage being the inability to identify completely novel or unexpected findings. However, the complete paucity of data on resistance to multi-targeted TKIs and, even more-so, intrinsic resistance to multi-targeted TKIs makes any information novel and valuable to this field. Nevertheless, the identification and collection of data from an independent replication cohort would be invaluable to the field. Another limitation of our study, inherent to its retrospective design, was the use of samples collected for clinical purposes as opposed to prospective collection for research purposes. However, the samples included in our study were all collected prior to multi-targeted TKI initiation, with the exception of one. The one individual with a sample collected after TKI treatment was intrinsically resistant to sorafenib, and we believe that any mutations that conferred intrinsic resistance would persist during and after TKI treatment.

We conducted an exploratory study to identify somatic point mutations, insertions/deletions, and copy number alterations characteristic in individuals with intrinsic resistance to multi-targeted TKIs. We identified potential predictors of resistance that each have biological plausibility; however, we acknowledge that multiple other factors may be important in determining who will respond to these agents. For example, pharmacokinetics and pharmacodynamics may affect drug penetration and exposure. Using MALDI-MSI (matrix-assisted laser desorption ionization mass spectrometry imaging) to visualize the distribution patterns of multi-targeted TKIs in mouse models, Torok and colleagues determined that poor drug penetration in some tumors resulted in primary resistance [47]. Clinical variability in drug concentrations, despite receiving the same dose, was associated with variability in side effects and survival outcomes [48, 49]. Lysosomal sequestration has also been demonstrated to confer resistance to the multi-targeted TKIs $[50,51]$ and was associated with conferring cross-resistance to the multi-targeted TKIs [52]. Finally, germline genetics in drug transporters, such as $A B C B 1$ and $A B C G 2$, or pharmacodynamic proteins, such as $B I M$, may also influence response to these agents [53-55]. While many factors must be considered when developing an optimized algorithm for predicting resistance in clinical practice, this study identified a combination of mutations and CNA that were associated with resistance to multi-targeted TKIs. With additional validation, preemptive identification of patients intrinsically resistant to multi-targeted TKIs will inform personalized treatment decisions to maximize outcomes while avoiding unnecessary exposures and toxicities.

\section{MATERIALS AND METHODS}

\section{Patient population}

Patients were identified from the Total Cancer Care (TCC) cohort at Moffitt Cancer Center, an institutional review board (IRB)-approved biobanking protocol (MCC14690, MCC13579) in which individuals agree to provide tissue and blood samples for research and to be followed throughout their lifetime [56]. Additional Moffitt Cancer Center Scientific Review Committee and IRB-approvals were granted to access tissue samples and conduct this particular study (MCC18790). Individuals eligible for study inclusion were patients consented between January 1, 1994 and December 31, 2015 over the age of 18 years diagnosed with any type of solid tumor and treated with a multi-targeted TKI (axitinib, cabozantinib, pazopanib, regorafenib, sorafenib, sunitinib, or vandetanib). Individuals were included if they had targeted exome sequencing or whole exome sequencing (WES) data available through the TCC protocol or if a tumor FFPE sample was available that could be used for DNA extraction and WES. Individuals treated with a multi-targeted TKI for a hematologic malignancy were excluded.

\section{Phenotyping}

Data was initially abstracted in a standardized manner from the TCC biorepository system (TransMed, 
Cupertino, CA). Data abstracted included demographic variables (date of birth, gender, race, and ethnicity) as well as clinical information [medical record numbers (MRNs), date of diagnosis, primary site at diagnosis, histology, first course of treatment, multi-targeted TKI received, start and stop date of TKI, and date of death or last follow-up]. Sources for these data were the Florida Cancer Registry and electronic medical records. Information abstracted from TransMed was used to guide manual chart reviews.

Two clinicians and researchers performed independent manual chart reviews using the patients' MRNs. Chart reviews included the validation of information generated using TransMed abstraction and manual review of patients' clinical notes and imaging (PET/CT/MRI) results before and after TKI administration. Data collected included radiologists' and clinicians' impressions of disease before and after TKI initiation (e.g., stable vs. progressive vs. responding, based on imaging studies) and time to drug change or discontinuation. Physicians' recommendations at first imaging follow-up (generally 2-3 months post-initiation) were used to identify patients intrinsically resistant to multi-targeted TKIs. The decision to stop TKI therapy due to cancer progression on imaging studies was classified as intrinsic resistance. Patients who continued TKI therapy due to response, stable disease, or mixed response on first imaging follow-up, and patients who met these criteria but stopped therapy due to side effects were classified as non-resistant. Individuals who stopped therapy early due to side effects or were lost to follow-up (i.e., those without first-imaging follow-up) could not confidently be classified were excluded from analyses. Based on these data, reviewers documented their individual impressions of patients as either resistant or non-resistant. Phenotype classifications were then compared and a third reviewer, a medical oncologist experienced with TKI prescribing and follow-up, provided adjudication when necessary.

\section{Next-generation sequencing and copy number alterations}

WES was performed in order to identify somatic mutations in the coding regions of the human genome. Briefly, $200 \mathrm{ng}$ of DNA, as quantified by qPCR, was used as input for library preparation with the SureSelect ${ }^{\mathrm{XT}}$ Reagent Kit (Agilent, Santa Clara, CA). For each tumor DNA sample, a genomic DNA library was constructed according to the SureSelect ${ }^{\mathrm{XT}}$ Target Enrichment for Illumina Multiplexed Sequencing (\#G7530-90000) protocol (Agilent), including the suggested modifications for FFPE-derived DNA samples. The pre-captured library was amplified, and the size and quality of the library was evaluated using a 2100 BioAnalzyer (Agilent) and Qubit ${ }^{\mathrm{TM}}$ quantification (Thermo Fisher Scientific, Waltham, MA). Approximately 500 to $750 \mathrm{ng}$ of pre-captured library was used for hybridization at $65^{\circ} \mathrm{C}$ for $24 \mathrm{hr}$. Hybridization and target enrichment were conducted using the SureSelect ${ }^{\mathrm{XT}}$ Clinical Research Exome kit (Agilent). The postcaptured library was amplified and evaluated with a 2100 Bioanalyzer (Agilent). The enriched library was quantified using a Library Quantification Kit for NGS (KAPA Biosystems, Wilmington, MA), and samples were diluted to a $4 \mathrm{nM}$ concentration. Denaturation was conducted using $\mathrm{NaOH}$, followed by neutralization with Tris buffer

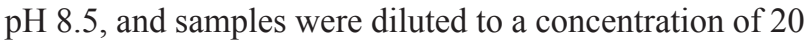
pM in HT1. Next, samples were diluted to concentrations between $1.7 \mathrm{pM}$ to $2.2 \mathrm{pM}$ for sequencing with a v2 sequencing reagent kit and a NextSeq 500 desktop sequencer (Illumina, San Diego, CA). Approximately 85 million 75 base paired-end reads were generated for each DNA sample.

Individuals with targeted gene sequencing data available had sequencing performed previously through collaboration with the Beijing Genomics Institute (Shenzhen, China). Briefly, tumor samples underwent targeted gene sequencing using a custom SureSelect platform (Agilent, Santa Clara, CA) targeting 1,321 cancer-related genes and 2 x 90bp massively parallel sequencing using a Genome Analyzer IIx (Illumina, San Diego, CA). In order to identify whole genome CNA and loss-of-heterozygosity, the OncoScan ${ }^{\circledR}$ FFPE Assay Kit (Affymetrix, Santa Clara, CA) was used according to the manufacturer's protocol, with an input of $80 \mathrm{ng}$ of FFPEextracted DNA.

\section{Candidate gene selection}

To decrease multiple comparison correction and increase the likelihood of identifying biologically plausible associations, we utilized a candidate gene approach for analysis. Candidate genes included genes known to be important in solid tumor biology and anticancer drug response were selected utilizing the overlapping genes reported on clinical cancer genetic testing platforms (such as FoundationOne ${ }^{\circledR}$ ) and those captured with the targeted sequencing platform designed specifically for the TCC study cohort (Supplementary Table 1).

\section{Data quality control and variant detection}

Whole exome sequencing reads were aligned to the reference human genome (hs37d5) with the BurrowsWheeler Aligner [57], and duplicate identification, insertion/deletion realignment, quality score recalibration, and variant identification were performed with Picard (Broad Institute, http://broadinstitute.github.io/picard/) and the Genome Analysis ToolKit (GATK) v2.2-Lite [58]. Genotypes were determined across all samples at variant positions. Sequence variants were annotated to determine genic context (i.e., non-synonymous, missense, splicing) using ANNOVAR [59], and summarized using spreadsheets and a genomic data visualization tool, 
VarSifter [60]. Additional contextual information from other studies was added, including allele frequency from 1000 Genomes [61] and the NHLBI Exome Sequence Project [62], in silico function impact predictions (PolyPhen and SIFT), and observed impacts from databases including ClinVar (NCBI, http://www.ncbi. nlm.nih.gov/clinvar/), the Catalogue of Somatic Mutations in Cancer (COSMIC) [63], and The Cancer Genome Atlas (TCGA, https://cancergenome.nih.gov/). Somatic mutations were prioritized by excluding variants observed in 1000 Genomes [61] and variants observed at $>5 \%$ in an internal dataset of adjacent normal (i.e., non-tumor) tissue. Variants with GATK variant quality score recalibration (VQSR) tranche $>99.9$ or genotype quality (GQ) $<15$ were excluded.

The CNA data generated was analyzed using Nexus Copy Number ${ }^{\mathrm{TM}} 6.0$ software (BioDiscovery, El Segundo, CA) utilizing the TuScan ${ }^{\mathrm{TM}}$ algorithm, specifically designed for OncoScan ${ }^{\circledR}$ FFPE Assay data [64]. The estimated CNA regions were annotated with the reference human genome (hg19) and the evaluation of array performance was measured using default criteria (MAPD $\leq 0.3$ and ndSNPQC $\geq 26$ ). Plots of whole genome CNAs and minor (or B) allele frequencies (BAFs) were generated for each individual. Briefly, the BAF was calculated as the count of minor $(\mathrm{B})$ alleles $(\mathrm{A} / \mathrm{T})$ divided by the total count of major $(A)(G / C)$ and minor $(B)$ alleles [65]. Using the TuScan ${ }^{\mathrm{TM}}$ algorithm the average CNA of all cells within each sample was generated. Genes with $70 \%$ or greater overlap in copy number aberrant regions were classified as being altered. Copy number gains greater than seven and homozygous losses were considered potentially clinically significant, as is standard in clinical tumor testing, and included in analyses.

\section{Data analysis}

Patients were classified into one of two cohorts: (1) resistant or (2) non-resistant using the phenotyping methods described above. Descriptive statistics were used to summarize demographic and clinical characteristics of patients included. Means, standard deviations and ranges were calculated for continuous variables, and frequencies and percentages were generated for categorical variables. As a conservative approach and where applicable, nonparametric statistical tests were implemented to avoid assuming the data was normally distributed. Demographic and clinical characteristic comparisons between resistant and non-resistant patients were performed using twotailed Fisher's exact tests for categorical variables and the Mann-Whitney $U$ test for continuous variables. Batch effects between the two sequencing methods and differences between tumor types were detected using a two-tailed Fisher's exact test and, when comparing between sequencing platforms, mutated genes with an FDR-corrected p-value $<0.05$ were excluded from further analyses. The two-tailed Fisher's exact test was used to test the statistical significance of mutated candidate genes identified in resistant and non-resistant patients. An FDR-corrected p-value $<0.1$ was considered statistically significant, and an uncorrected p-value $<0.1$ was significant for exploratory associations. Cytoscape (v.3.4.0) Enrichment Map [66] was utilized to conduct gene set enrichment of top gene hits, and the Genomics in Drug Sensitivity in Cancer database [67] was utilized to explore in vivo-derived predictions of sensitivity to multitargeted TKIs based on mutation status of the top hits.

For CNA analysis, copy number gains and losses were grouped. Presence of copy number aberrations between resistant and non-resistant individuals were arranged in contingency tables and analyzed using a twosided Fisher's exact test. FDR-corrected p-values $<0.1$ were considered statistically significant, and a threshold of FDR-corrected $\mathrm{p}<0.3$ was used for exploratory analysis [68, 69]. Cytoscape (v.3.4.0) Enrichment Map [66] was utilized to conduct gene set enrichment of top gene hits.

Statistical analysis was conducted using the opensource, statistical programming language, $\mathrm{R}$ (version 3.3.2) [70]. CNA and WES data were combined to build a model leveraging both technologies. CNAs were annotated as 1 , $0,-1$ for gain, no change, or loss, respectively, based on the criteria described above. Subjects with $>20 \%$ missing data and genes with $>5 \%$ missing data were excluded from further analysis. Remaining missing genes were imputed using the mean of the study cohort. Subsequently, feature reduction, via a random forest model was constructed using 2000 trees and 12 features at each split [71]. CNA and WES features with a mean decrease in Gini score $>0.2$, as determined using the elbow method, were selected for inclusion in the decision tree classification model using recursive partitioning trees [72]. Figures were generated using R (version 3.3.2) and GraphPad Prism 6.

\section{Abbreviations}

BAF: minor (or B) allele frequencies

CNA: copy number alteration

CT: computed tomography

cyclin D: cyclin-dependent

EGFR: epidermal growth factor receptor

FDA: United States Food and Drug Administration

FDR: false discovery rate

FFPE: formalin-fixed paraffin-embedded

GATK: Genome Analysis ToolKit

GQ: genotype quality

IRB: institutional review board

MALDI-MSI: matrix-assisted laser desorption

ionization mass spectrometry imaging

MRI: magnetic resonance imaging

MRN: medical record numbers

PET: positron emission tomography

TCC: Total Cancer Care 
TCGA: The Cancer Genome Atlas

TKIs: tyrosine kinase inhibitor

VQSR: variant quality score recalibration

WES: whole exome sequencing.

\section{Author contributions}

All authors were involved in the preparation of this manuscript. HLM is the Prinicipal Investigator and was involved in all aspects of the study. NKG contributed to study design, patient identification, data collection and interpretation, and writing of the manuscript. DMR and JKT were involved in study design, data analysis, and interpretation. SJY, TEM, and MC were involved in data collection. CMW was involved in study design, data collection, and interpretation.

\section{CONFLICTS OF INTEREST}

The authors declared no conflicts of interest.

\section{FUNDING}

The DeBartolo Family Personalized Medicine Institute, the State of Florida Cancer Research Endowed Chair, the Collins Charitable Foundation, the American Foundation for Pharmaceutical Education, and the University of North Carolina Graduate School. This work has been supported in part by the Tissue Core, Molecular Genomics Core, Collaborative Data Services Core, and Cancer Informatics Core Facilities at the H. Lee Moffitt Cancer Center \& Research Institute, an NCI designated Comprehensive Cancer Center (P30-CA076292).

\section{REFERENCES}

1. McLeod H. Graying anatomy? Toward molecular tumor characterization. Pharmacogenomics. 2007; 8: 15-6. https:// doi.org/10.2217/14622416.8.1.15.

2. Cancer Genome Atlas Network. Comprehensive molecular portraits of human breast tumours. Nature. 2012; 490: 61-70. https://doi.org/10.1038/nature11412.

3. Hoadley KA, Yau C, Wolf DM, Cherniack AD, Tamborero $\mathrm{D}, \mathrm{Ng} \mathrm{S}$, Leiserson MD, Niu B, McLellan MD, Uzunangelov V, Zhang J, Kandoth C, Akbani R, et al. Multiplatform analysis of 12 cancer types reveals molecular classification within and across tissues of origin. Cell. 2014; 158: 929-44. https://doi.org/10.1016/j.cell.2014.06.049.

4. Redig AJ, Janne PA. Basket trials and the evolution of clinical trial design in an era of genomic medicine. J Clin Oncol. 2015; 33: 975-7. https://doi.org/10.1200/ JCO.2014.59.8433.

5. Gillis NK, McLeod HL. The pharmacogenomics of drug resistance to protein kinase inhibitors. Drug Resist Updat. 2016; 28: 28-42. https://doi.org/10.1016/j.drup.2016.06.008.
6. Brose MS, Nutting CM, Jarzab B, Elisei R, Siena S, Bastholt L, de la Fouchardiere C, Pacini F, Paschke R, Shong YK, Sherman SI, Smit JW, Chung J, et al. Sorafenib in radioactive iodine-refractory, locally advanced or metastatic differentiated thyroid cancer: a randomised, double-blind, phase 3 trial. Lancet. 2014; 384: 319-28. https://doi.org/10.1016/S0140-6736(14)60421-9.

7. Demetri GD, Reichardt P, Kang YK, Blay JY, Rutkowski P, Gelderblom H, Hohenberger P, Leahy M, von Mehren M, Joensuu H, Badalamenti G, Blackstein M, Le Cesne A, et al. Efficacy and safety of regorafenib for advanced gastrointestinal stromal tumours after failure of imatinib and sunitinib (GRID): an international, multicentre, randomised, placebo-controlled, phase 3 trial. Lancet. 2013; 381: 295302. https://doi.org/10.1016/S0140-6736(12)61857-1.

8. Escudier B, Eisen T, Stadler WM, Szczylik C, Oudard S, Siebels M, Negrier S, Chevreau C, Solska E, Desai AA, Rolland F, Demkow T, Hutson TE, et al. Sorafenib in advanced clear-cell renal-cell carcinoma. N Engl J Med. 2007; 356: 125-34. https://doi.org/10.1056/ NEJMoa060655.

9. Llovet JM, Ricci S, Mazzaferro V, Hilgard P, Gane E, Blanc JF, de Oliveira AC, Santoro A, Raoul JL, Forner A, Schwartz M, Porta C, Zeuzem S, et al. Sorafenib in advanced hepatocellular carcinoma. N Engl J Med. 2008; 359: 378-90. https://doi.org/10.1056/NEJMoa0708857.

10. Motzer RJ, Hutson TE, Tomczak P, Michaelson MD, Bukowski RM, Rixe O, Oudard S, Negrier S, Szczylik C, Kim ST, Chen I, Bycott PW, Baum CM, et al. Sunitinib versus interferon alfa in metastatic renal-cell carcinoma. N Engl J Med. 2007; 356: 115-24. https://doi.org/10.1056/ NEJMoa065044.

11. Raymond E, Dahan L, Raoul JL, Bang YJ, Borbath I, Lombard-Bohas C, Valle J, Metrakos P, Smith D, Vinik A, Chen JS, Horsch D, Hammel P, et al. Sunitinib malate for the treatment of pancreatic neuroendocrine tumors. $\mathrm{N}$ Engl J Med. 2011; 364: 501-13. https://doi.org/10.1056/ NEJMoa1003825.

12. Sternberg CN, Davis ID, Mardiak J, Szczylik C, Lee E, Wagstaff J, Barrios CH, Salman P, Gladkov OA, Kavina A, Zarba JJ, Chen M, McCann L, et al. Pazopanib in locally advanced or metastatic renal cell carcinoma: results of a randomized phase III trial. J Clin Oncol. 2010; 28: 1061-8. https://doi.org/10.1200/JCO.2009.23.9764.

13. Wells SA Jr, Robinson BG, Gagel RF, Dralle H, Fagin JA, Santoro M, Baudin E, Elisei R, Jarzab B, Vasselli JR, Read J, Langmuir P, Ryan AJ, et al. Vandetanib in patients with locally advanced or metastatic medullary thyroid cancer: a randomized, double-blind phase III trial. J Clin Oncol. 2012; 30: 134-41. https://doi.org/10.1200/JCO.2011.35.5040.

14. Garnett MJ, Edelman EJ, Heidorn SJ, Greenman CD, Dastur A, Lau KW, Greninger P, Thompson IR, Luo X, Soares J, Liu Q, Iorio F, Surdez D, et al. Systematic identification of genomic markers of drug sensitivity in cancer cells. Nature. 2012; 483: 570-5. https://doi.org/10.1038/nature11005. 
15. Iorio F, Knijnenburg TA, Vis DJ, Bignell GR, Menden MP, Schubert M, Aben N, Goncalves E, Barthorpe S, Lightfoot H, Cokelaer T, Greninger P, van Dyk E, et al. A landscape of pharmacogenomic interactions in cancer. cell. 2016; 166: 740-54. https://doi.org/10.1016/j.cell.2016.06.017.

16. Anastassiadis T, Deacon SW, Devarajan K, Ma H, Peterson JR. Comprehensive assay of kinase catalytic activity reveals features of kinase inhibitor selectivity. Nat Biotechnol. 2011; 29: 1039-45. https://doi.org/10.1038/nbt.2017.

17. Arao T, Matsumoto K, Furuta K, Kudo K, Kaneda H, Nagai T, Sakai K, Fujita Y, Tamura D, Aomatsu K, Koizumi F, Nishio K. Acquired drug resistance to vascular endothelial growth factor receptor 2 tyrosine kinase inhibitor in human vascular endothelial cells. Anticancer Res. 2011; 31: 2787-96.

18. Stubbs C, Bardoli AD, Afshar M, Pirrie S, Miscoria M, Wheeley I, Porfiri E. A study of angiogenesis markers in patients with renal cell carcinoma undergoing therapy with sunitinib. Anticancer Res. 2017; 37: 253-9. https://doi. org/10.21873/anticanres.11315.

19. Kampmann E, Altendorf-Hofmann A, Gibis S, Lindner LH, Issels R, Kirchner T, Knosel T. VEGFR2 predicts decreased patients survival in soft tissue sarcomas. Pathol Res Pract. 2015; 211: 726-30. https://doi.org/10.1016/j. prp.2015.04.015.

20. Cerami E, Gao J, Dogrusoz U, Gross BE, Sumer SO, Aksoy BA, Jacobsen A, Byrne CJ, Heuer ML, Larsson E, Antipin Y, Reva B, Goldberg AP, et al. The cBio cancer genomics portal: an open platform for exploring multidimensional cancer genomics data. Cancer Discov. 2012; 2: 401-4. https://doi.org/10.1158/2159-8290.CD-12-0095.

21. Gao J, Aksoy BA, Dogrusoz U, Dresdner G, Gross B, Sumer SO, Sun Y, Jacobsen A, Sinha R, Larsson E, Cerami E, Sander C, Schultz N. Integrative analysis of complex cancer genomics and clinical profiles using the cBioPortal. Sci Signal. 2013; 6: pl1. https://doi.org/10.1126/ scisignal.2004088.

22. Kamiya A, Inokuchi M, Otsuki S, Sugita H, Kato K, Uetake H, Sugihara K, Takagi Y, Kojima K. Prognostic value of tropomyosin-related kinases $\mathrm{A}, \mathrm{B}$, and $\mathrm{C}$ in gastric cancer. Clin Transl Oncol. 2016; 18: 599-607. https://doi. org/10.1007/s12094-015-1407-7.

23. Lagadec C, Meignan S, Adriaenssens E, Foveau B, Vanhecke E, Romon R, Toillon RA, Oxombre B, Hondermarck H, Le Bourhis X. TrkA overexpression enhances growth and metastasis of breast cancer cells. Oncogene. 2009; 28: 1960-70. https://doi.org/10.1038/ onc.2009.61.

24. Pasini L, Re A, Tebaldi T, Ricci G, Boi S, Adami V, Barbareschi M, Quattrone A. TrkA is amplified in malignant melanoma patients and induces an anti-proliferative response in cell lines. BMC Cancer. 2015; 15: 777. https:// doi.org/10.1186/s12885-015-1791-y.

25. Russo M, Misale S, Wei G, Siravegna G, Crisafulli G, Lazzari L, Corti G, Rospo G, Novara L, Mussolin B,
Bartolini A, Cam N, Patel R, et al. Acquired resistance to the TRK inhibitor entrectinib in colorectal cancer. Cancer Discov. 2016; 6: 36-44. https://doi.org/10.1158/2159-8290. CD-15-0940.

26. Busch J, Seidel C, Weikert S, Wolff I, Kempkensteffen C, Weinkauf L, Hinz S, Magheli A, Miller K, Grunwald $\mathrm{V}$. Intrinsic resistance to tyrosine kinase inhibitors is associated with poor clinical outcome in metastatic renal cell carcinoma. BMC Cancer. 2011; 11: 295. https://doi. org/10.1186/1471-2407-11-295.

27. Gao N, Zhai Q, Li Y, Huang K, Bian D, Wang X, Liu C, Xu $\mathrm{H}$, Zhang T. Clinical implications of TbetaRII expression in breast cancer. PLoS One. 2015; 10: e0141412. https://doi. org/10.1371/journal.pone.0141412.

28. Lei J, Rudolph A, Moysich KB, Rafiq S, Behrens S, Goode EL, Pharoah PP, Seibold P, Fasching PA, Andrulis IL, Kristensen VN, Couch FJ, Hamann U, et al. Assessment of variation in immunosuppressive pathway genes reveals TGFBR2 to be associated with prognosis of estrogen receptor-negative breast cancer after chemotherapy. Breast Cancer Res. 2015; 17: 18. https://doi.org/10.1186/ s13058-015-0522-2.

29. Bian J, Li B, Zeng X, Hu H, Hong Y, Ouyang H, Zhang X, Wang Z, Zhu H, Lei P, Huang B, Shen G. Mutation of TGFbeta receptor II facilitates human bladder cancer progression through altered TGF-betal signaling pathway. Int J Oncol. 2013; 43: 1549-59. https://doi.org/10.3892/ijo.2013.2065.

30. Nadauld LD, Garcia S, Natsoulis G, Bell JM, Miotke L, Hopmans ES, Xu H, Pai RK, Palm C, Regan JF, Chen H, Flaherty P, Ootani A, et al. Metastatic tumor evolution and organoid modeling implicate TGFBR2 as a cancer driver in diffuse gastric cancer. Genome Biol. 2014; 15: 428. https:// doi.org/10.1186/s13059-014-0428-9.

31. Park I, Son HK, Che ZM, Kim J. A novel gain-of-function mutation of TGF-beta receptor II promotes cancer progression via delayed receptor internalization in oral squamous cell carcinoma. Cancer Lett. 2012; 315: 161-9. https://doi.org/10.1016/j.canlet.2011.09.036.

32. Han T, Xiang DM, Sun W, Liu N, Sun HL, Wen W, Shen WF, Wang RY, Chen C, Wang X, Cheng Z, Li HY, Wu $\mathrm{MC}$, et al. PTPN11/Shp2 overexpression enhances liver cancer progression and predicts poor prognosis of patients. J Hepatol. 2015; 63: 651-60. https://doi.org/10.1016/j. jhep.2015.03.036.

33. Hu Z, Wang X, Fang H, Liu Y, Chen D, Zhang Q, Liu X, Wei D, Qu C, Wang S. A tyrosine phosphatase SHP2 gain-of-function mutation enhances malignancy of breast carcinoma. Oncotarget. 2016; 7: 5664-76. https://doi. org/10.18632/oncotarget.6561.

34. Wang HC, Chiang WF, Huang HH, Shen YY, Chiang HC. Src-homology 2 domain-containing tyrosine phosphatase 2 promotes oral cancer invasion and metastasis. BMC Cancer. 2014; 14: 442. https://doi.org/10.1186/1471-2407-14-442.

35. Furcht CM, Buonato JM, Skuli N, Mathew LK, Munoz Rojas AR, Simon MC, Lazzara MJ. Multivariate signaling 
regulation by SHP2 differentially controls proliferation and therapeutic response in glioma cells. J Cell Sci. 2014; 127 : 3555-67. https://doi.org/10.1242/jcs.150862.

36. Zhuo C, Shao M, Chen C, Lin C, Jiang D, Chen G, Tian H, Wang L, Li J, Lin X. Chemotherapy effectiveness and prognosis of gastric cancer influenced by PTPN11 polymorphisms. Cell Physiol Biochem. 2016; 39: 1537-52. https://doi.org/10.1159/000447856.

37. Prahallad A, Heynen GJ, Germano G, Willems SM, Evers B, Vecchione L, Gambino V, Lieftink C, Beijersbergen RL, Di Nicolantonio F, Bardelli A, Bernards R. PTPN11 is a central node in intrinsic and acquired resistance to targeted cancer drugs. Cell Rep. 2015; 12: 1978-85. https://doi. org/10.1016/j.celrep.2015.08.037.

38. Musgrove EA, Caldon CE, Barraclough J, Stone A, Sutherland RL. Cyclin D as a therapeutic target in cancer. Nat Rev Cancer. 2011; 11: 558-72. https://doi.org/10.1038/ nrc3090.

39. Knosel T, Altendorf-Hofmann A, Lindner L, Issels R, Hermeking H, Schuebbe G, Gibis S, Siemens H, Kampmann E, Kirchner T. Loss of p16(INK4a) is associated with reduced patient survival in soft tissue tumours, and indicates a senescence barrier. J Clin Pathol. 2014; 67: 5928. https://doi.org/10.1136/jclinpath-2013-202106.

40. Day BW, Stringer BW, Al-Ejeh F, Ting MJ, Wilson J, Ensbey KS, Jamieson PR, Bruce ZC, Lim YC, Offenhauser C, Charmsaz S, Cooper LT, Ellacott JK, et al. EphA3 maintains tumorigenicity and is a therapeutic target in glioblastoma multiforme. Cancer Cell. 2013; 23: 238-48. https://doi.org/10.1016/j.ccr.2013.01.007.

41. Lu CY, Yang ZX, Zhou L, Huang ZZ, Zhang HT, Li J, Tao KS, Xie BZ. High levels of EphA3 expression are associated with high invasive capacity and poor overall survival in hepatocellular carcinoma. Oncol Rep. 2013; 30: 2179-86. https://doi.org/10.3892/or.2013.2679.

42. Xi HQ, Wu XS, Wei B, Chen L. Aberrant expression of EphA3 in gastric carcinoma: correlation with tumor angiogenesis and survival. J Gastroenterol. 2012; 47: 78594. https://doi.org/10.1007/s00535-012-0549-4.

43. Peng J, Wang Q, Liu H, Ye M, Wu X, Guo L. EPHA3 regulates the multidrug resistance of small cell lung cancer via the PI3K/ BMX/STAT3 signaling pathway. Tumour Biol. 2016; 37: 11959-71. https://doi.org/10.1007/s13277-016-5048-4.

44. Honma K, Tsuzuki S, Nakagawa M, Tagawa H, Nakamura S, Morishima Y, Seto M. TNFAIP3/A20 functions as a novel tumor suppressor gene in several subtypes of nonHodgkin lymphomas. Blood. 2009; 114: 2467-75. https:// doi.org/10.1182/blood-2008-12-194852.

45. Vendrell JA, Ghayad S, Ben-Larbi S, Dumontet C, Mechti N, Cohen PA. A20/TNFAIP3, a new estrogen-regulated gene that confers tamoxifen resistance in breast cancer cells. Oncogene. 2007; 26: 4656-67. https://doi.org/10.1038/sj.onc.1210269.

46. Bredel M, Bredel C, Juric D, Duran GE, Yu RX, Harsh GR, Vogel H, Recht LD, Scheck AC, Sikic BI. Tumor necrosis factor- $\alpha$-induced protein 3 down-regulates nuclear factor$\kappa \mathrm{B}-$ mediated drug resistance in vitro and is a favorable clinical prognostic factor in human glioblastomas. J Clin Oncol. 2006; 24: 1508.

47. Torok S, Rezeli M, Kelemen O, Vegvari A, Watanabe K, Sugihara Y, Tisza A, Marton T, Kovacs I, Tovari J, Laszlo V, Helbich TH, Hegedus B, et al. Limited tumor tissue drug penetration contributes to primary resistance against angiogenesis inhibitors. Theranostics. 2017; 7: 400-12. https://doi.org/10.7150/thno.16767.

48. Lankheet NA, Kloth JS, Gadellaa-van Hooijdonk CG, Cirkel GA, Mathijssen RH, Lolkema MP, Schellens JH, Voest EE, Sleijfer S, de Jonge MJ, Haanen JB, Beijnen JH, Huitema AD, et al. Pharmacokinetically guided sunitinib dosing: a feasibility study in patients with advanced solid tumours. Br J Cancer. 2014; 110: 2441-9. https://doi. org/10.1038/bjc.2014.194.

49. Suttle AB, Ball HA, Molimard M, Hutson TE, Carpenter C, Rajagopalan D, Lin Y, Swann S, Amado R, Pandite L. Relationships between pazopanib exposure and clinical safety and efficacy in patients with advanced renal cell carcinoma. Br J Cancer. 2014; 111: 1909-16. https://doi. org/10.1038/bjc.2014.503.

50. Giuliano S, Cormerais Y, Dufies M, Grepin R, Colosetti P, Belaid A, Parola J, Martin A, Lacas-Gervais S, Mazure NM, Benhida R, Auberger P, Mograbi B, et al. Resistance to sunitinib in renal clear cell carcinoma results from sequestration in lysosomes and inhibition of the autophagic flux. Autophagy. 2015; 11: 1891-904. https://doi.org/10.10 80/15548627.2015.1085742.

51. Gotink KJ, Broxterman HJ, Labots M, de Haas RR, Dekker $\mathrm{H}$, Honeywell RJ, Rudek MA, Beerepoot LV, Musters RJ, Jansen G, Griffioen AW, Assaraf YG, Pili R, et al. Lysosomal sequestration of sunitinib: a novel mechanism of drug resistance. Clin Cancer Res. 2011; 17: 7337-46. https://doi.org/10.1158/1078-0432.CCR-11-1667.

52. Gotink KJ, Rovithi M, de Haas RR, Honeywell RJ, Dekker H, Poel D, Azijli K, Peters GJ, Broxterman HJ, Verheul HM. Cross-resistance to clinically used tyrosine kinase inhibitors sunitinib, sorafenib and pazopanib. Cell Oncol (Dordr). 2015; 38: 119-29. https://doi.org/10.1007/ s13402-015-0218-8.

53. Ng KP, Hillmer AM, Chuah CT, Juan WC, Ko TK, Teo AS, Ariyaratne PN, Takahashi N, Sawada K, Fei Y, Soh $\mathrm{S}$, Lee WH, Huang JW, et al. A common BIM deletion polymorphism mediates intrinsic resistance and inferior responses to tyrosine kinase inhibitors in cancer. Nat Med. 2012; 18: 521-8. https://doi.org/10.1038/nm.2713.

54. Wu SG, Liu YN, Yu CJ, Yang PC, Shih JY. Association of BIM deletion polymorphism with intrinsic resistance to EGFR tyrosine kinase inhibitors in patients with lung adenocarcinoma. JAMA Oncol. 2016; 2: 826-8. https://doi. org/10.1001/jamaoncol.2016.0016.

55. Goler-Baron V, Assaraf YG. Structure and function of ABCG2-rich extracellular vesicles mediating multidrug 
resistance. PLoS One. 2011; 6: e16007. https://doi. org/10.1371/journal.pone.0016007.

56. Fenstermacher DA, Wenham RM, Rollison DE, Dalton WS. Implementing personalized medicine in a cancer center. Cancer J. 2011; 17: 528-36. https://doi.org/10.1097/ PPO.0b013e318238216e.

57. Li H, Durbin R. Fast and accurate short read alignment with Burrows-Wheeler transform. Bioinformatics. 2009; 25: 1754-60. https://doi.org/10.1093/bioinformatics/btp324.

58. DePristo MA, Banks E, Poplin R, Garimella KV, Maguire JR, Hartl C, Philippakis AA, del Angel G, Rivas MA, Hanna M, McKenna A, Fennell TJ, Kernytsky AM, et al. A framework for variation discovery and genotyping using next-generation DNA sequencing data. Nat Genet. 2011; 43: 491-8. https://doi.org/10.1038/ng.806.

59. Wang K, Li M, Hakonarson H. ANNOVAR: functional annotation of genetic variants from high-throughput sequencing data. Nucleic Acids Res. 2010; 38: e164. https:// doi.org/10.1093/nar/gkq603.

60. Teer JK, Green ED, Mullikin JC, Biesecker LG. VarSifter: visualizing and analyzing exome-scale sequence variation data on a desktop computer. Bioinformatics. 2012; 28: 599600. https://doi.org/10.1093/bioinformatics/btr711.

61. Auton A, Brooks LD, Durbin RM, Garrison EP, Kang HM, Korbel JO, Marchini JL, McCarthy S, McVean GA, Abecasis GR, and 1000 Genomes Project Consortium. A global reference for human genetic variation. Nature. 2015; 526: 68-74. https://doi.org/10.1038/nature15393.

62. Auer PL, Reiner AP, Wang G, Kang HM, Abecasis GR, Altshuler D, Bamshad MJ, Nickerson DA, Tracy RP, Rich SS, Leal SM, NHLBI GO Exome Sequencing Project NGES. Guidelines for large-scale sequence-based complex trait Association studies: lessons learned from the NHLBI exome sequencing project. Am J Hum Genet. 2016; 99: 791-801. https://doi.org/10.1016/j.ajhg.2016.08.012.

63. Forbes SA, Beare D, Boutselakis H, Bamford S, Bindal N, Tate J, Cole CG, Ward S, Dawson E, Ponting L, Stefancsik R, Harsha B, Kok CY, et al. COSMIC: somatic cancer genetics at high-resolution. Nucleic Acids Res. 2017; 45: D777-83. https://doi.org/10.1093/nar/gkw1121.
64. Schmidt J, Liu B, Ghent M, Bolstad B, Siddiqui F, Abdueva D, Marjanovic M, Saplosky R, Shukla A, Venkatapathy S, Chen C, Bruckner C, Huynh V, et al. (2014). A New Method for High Fidelity Copy Number Analysis in Solid Tumor Samples and its implementation in the OncoScan ${ }^{\mathrm{TM}}$ FFPE Assay Kit. American Society of Human Genetics (ASHG). 64th Annual Meeting, San Diego, CA: Abstract \#3330M.

65. Alkan C, Coe BP, Eichler EE. Genome structural variation discovery and genotyping. Nat Rev Genet. 2011; 12: 36376. https://doi.org/10.1038/nrg2958.

66. Merico D, Isserlin R, Stueker O, Emili A, Bader GD. Enrichment map: a network-based method for geneset enrichment visualization and interpretation. PLoS One. 2010; 5: e13984. https://doi.org/10.1371/journal. pone. 0013984.

67. Yang W, Soares J, Greninger P, Edelman EJ, Lightfoot H, Forbes S, Bindal N, Beare D, Smith JA, Thompson IR, Ramaswamy S, Futreal PA, Haber DA, et al. Genomics of Drug Sensitivity in Cancer (GDSC): a resource for therapeutic biomarker discovery in cancer cells. Nucleic Acids Res. 2013; 41: D955-61. https://doi.org/10.1093/nar/ gks1111.

68. Benjamini Y, Hochberg Y. Controlling the false discovery rate: a practical and powerful approach to multiple testing. J R Stat Soc Series B Stat Methodol. 1995; 57: 289-300.

69. Tan EH, Ramlau R, Pluzanska A, Kuo HP, Reck M, Milanowski J, Au JS, Felip E, Yang PC, Damyanov D, Orlov S, Akimov M, Delmar P, et al. A multicentre phase II gene expression profiling study of putative relationships between tumour biomarkers and clinical response with erlotinib in non-small-cell lung cancer. Ann Oncol. 2010; 21: 217-22. https://doi.org/10.1093/annonc/mdp520.

70. R Development Core Team. (2016). R: A language and environment for statistical computing. Vienna, Austria: R Foundation for Statistical Computing. Retrieved from http:// www.R-project.org.

71. Liaw A, Wiener M. Classification and Regression by randomForest. R News. 2002; 2: 18-22.

72. Therneau T, Atkinson B, Ripley B. (2015). rpart: Recursive Partitioning and Regression Trees. R package version 4.110. https://CRAN.R-project.org/package=rpart. 